\title{
PERBANDINGAN AKTIVITAS HARIAN DUA KELOMPOK MONYET HITAM SULAWESI (Macaca nigra) DI CAGAR ALAM TANGKOKO-BATUANGUS, SULAWESI UTARA
}

\author{
Deidy Katili $^{1)}$ dan Saroyo ${ }^{\text {1) }}$ \\ ${ }^{1)}$ Program Studi Biologi, FMIPA, Universitas Sam Ratulangi, \\ Jl. Kampus UNSRAT Manado 95115; e-mail: saroyos@yahoo.com
}

\begin{abstract}
ABSTRAK
Telah dilakukan penelitian tentang perbandingan aktivitas harian dua kelompok monyet hitam Sulawesi (Macaca nigra) di Cagar Alam Tangkoko-Batuangus, Sulawesi Utara dengan tujuan untuk menganalisis perbedaan frekuensi aktivitas harian pada kondisi habitat yang berbeda. Penelitian dilaksanakan pada bulan Januari sampai dengan Desember 2009 pada dua kelompok Macaca nigra terhabituasi, yaitu kelompok Rambo I (KRI) dan kelompok Rambo II (KRII). KRI lebih banyak menempati hutan primer, sedangkan KRII lebih banyak menempati hutan sekunder dan semak belukar. Aktivitas harian dibedakan menjadi 5 kelas, yaitu makan (feeding), mencari makan (foraging), berpindah (moving), istirahat (resting), dan sosial (social). Data aktivitas harian diambil dengan menggunakan metode focal animal sampling dengan interval 2 menit dari jam 06.00 sampai jam 18.00. Hasil penelitian menunjukkan bahwa kedua kelompok memiliki frekuensi aktivitas yang berbeda tetapi hasil uji Chi-Square menunjukkan frekuensi aktivitas makan kedua kelompok tersebut tidak berbeda nyata. Aktivitas terbanyak yang dilakukan oleh kedua kelompok tersebut adalah makan.
\end{abstract}

Kata kunci: aktivitas harian, cagar alam Tangkoko-Batuangus, Macaca nigra,

\section{COMPARISON OF DAILY ACTIVITIES BETWEEN TWO GROUPS OF SULAWESI-CRESTED-BLACK-MACAQUES (Macaca nigra) AT TANGKOKO- BATUANGUS NATURE RESERVE, NORTH SULAWESI}

\begin{abstract}
The comparison of daily activities between two groups of Sulawesi-crested-black-macaques (Macaca nigra) was studied at Tangkoko-Batuangus Nature Reserve, North Sulawesi. This study aimed to analyze the different of daily activities frequency in the different habitat condition. This research was conducted on two habituated group in January to December 2009. The first group was Rambi I that was accupied in the primary forest and the second group was that was occupied in the secondary forest as well as in the shurb. The daily activities were grouped into 5 classes, i.e. feeding, foraging, moving, resting, and social. Daily activity data were collected using focalanimal- sampling from 06.00 a.m. to 06.00 p.m with 2 minutes interval. The results showed the different frequency of daily activities between the groups, however, the differences were not significant based on Chi-Square test. The highest frequency of daily activity was feeding.
\end{abstract}

Keywords: daily activities, Tangkoko-Batuangus Nature Reserve, Macaca nigra

\section{PENDAHULUAN}

Sulawesi merupakan pulau terbesar di dalam Kawasan Wallacea. Wallacea adalah daerah peralihan antara Zoogeografi Oriental dan Zoogeografi. Satwa Sulawesi merupakan yang paling khas di seluruh Indonesia terutama di antara mammalia (Whitten et al.,
1987). Dari 127 spesies mammalia asli, 62\% bersifat endemik. Monyet (genus Macaca) adalah satwa khas Oriental yang daerah penyebarannya sampai di Sulawesi. Nenek moyang monyet Sulawesi menyeberang ke Pulau Sulawesi pada pertengahan Plestosen dari Pulau Kalimantan atau Jawa. Pada saat ini terdapat enam spesies monyet endemik 
Sulawesi, yaitu Macaca nigra, Macaca nigrescens, Macaca hecki, Macaca tonkeana, Macaca maura (M. maurus), dan Macaca ochreata (Groves 2001), atau tujuh spesies menurut Fooden (1969 dalam Bynum 1999) dengan tambahan Macaca brunnescens.

Monyet hitam Sulawesi (Macaca nigra) menempati habitat hutan hujan tropis primer dan sekunder di beberapa lokasi di semenanjung utara Pulau Sulawesi dan beberapa pulau satelitnya (Lee dan Kussoy 1999, Supriatna dan Wahyono 2000). Salah satu lokasi habitat monyet hitam Sulawesi (Macaca nigra) tersebut adalah Cagar Alam Tangkoko-Batuangus dan Taman Wisata Alam Batuputih di Kota Bitung, Sulawesi Utara.

Pada umumnya monyet hidup berkelompok yang terdiri dari 30-100 ekor. Hidup berkelompok ini mengharuskan setiap individu untuk membagi aktivitas hidupnya di tempat-tempat yang berbeda guna mengurangi peluang terjadinya kompetisi antarindividu di dalam satu kelompok atau antarkelompok. Pemanfaatan hutan sebagai habitat dalam pemenuhan kebutuhan pokok Macaca nigra didasarkan pada strata hutan yang merupakan karakteristik hutan hujan tropis. Jenis ini memanfaatkan setiap stratum dalam menjalankan aktivitas hariannya, yaitu makan (feeding), mencari makan (foraging), berpindah (moving), istirahat (resting), dan sosial (social).

Penelitian tentang aktivitas harian pada Macaca nigra pernah dilakukan pada bulan Januari 1993 sampai dengan Juni 1994 pada 3 kelompok besar, termasuk Kelompok Rambo yang mempunyai ukuran 97 ekor (O,brien \& Kinnaird, 1997). Hasil penelitian menunjukkan bahwa aktivitas harian kelompok ini adalah: makan $25,1 \%$; mencari makan 9,0\%; berpindah 18,3\%; istirahat $28,9 \%$; dan sosial $18,7 \%$. Tetapi pada tahun 1994, Kelompok Rambo terfragmentasi menjadi 2 kelompok yang lebih kecil, yaitu Kelompok Rambo I dan kelompok Rambo II dengan daerah jelajah yang berbeda dan dengan karakteristik habitat yang berbeda. Kedua kelompok tersebut stabil pada ukuran 60-70 ekor.

Dengan demikian perbedaan habitat dapat menyebabkan perbedaan dalam pemanfaatannya yang dapat dianalisis dari persentase aktivitas hariannya. Oleh karena itu maka dilakukan penelitian pada dua kelompok yang mempunyai tipe habitat yang berbeda.

\section{METODOLOGI PENELITIAN}

\section{Waktu dan Tempat Penelitian}

Penelitian dilaksanakan pada bulan Januari sampai dengan Desember 2009 di Cagar Alam Tangkoko-Batuangus, Kota Bitung, Sulawesi Utara.

\section{Metode Penelitian}

Materi penelitian adalah dua kelompok Macaca nigra terhabituasi, yaitu kelompok Rambo I (KRI) dan kelompok Rambo II (KRII). Kedua kelompok mempunyai ukuran yang hampir sama, yaitu sekitar 60 ekor, tetapi berbeda dalam tipe habitatnya. KRI lebih banyak menempati hutan primer, sedangkan KRII lebih banyak menempati hutan sekunder dan semak belukar.

Aktivitas harian dibedakan menjadi 5 kelas, yaitu makan (feeding), mencari makan (foraging), berpindah (moving), istirahat (resting), dan sosial (social) (O,brien \& Kinnaird, 1997). Aktivitas makan adalah aktivitas monyet mengambil makanan, memasukkan makanan ke dalam mulut, menyimpannya dalam kantung pipi, dan mengunyah, serta menelan makanan. Mencari makan adalah aktivitas monyet memanjat pohon untuk mencari makanan, meraih makanan, menangkap serangga, membolakbalik daun atau serasah, dan sebagainya. Berpindah merupakan aktivitas berjalan, berlari atau melompat untuk meninggalkan satu lokasi menuju lokasi lainnya. Istirahat merupakan aktivitas duduk di tanah atau pohon, autogrooming, tidur, atau tiduran tanpa melakukan aktivitas lainnya. Sosial merupakan aktivitas yang berkaitan dengan kehidupan kelompok, seperti allogrooming, berkelahi, seksual, dan bermain.

Data aktivitas harian diambil dengan menggunakan metode focal animal sampling (Martin \& Bateson, 1999) dengan interval 2 menit dari jam 06.00 sampai jam 18.00. Setiap hari pengamatan hanya dilakukan terhadap satu ekor monyet.

Analisis data dilakukan dengan menghitung frekuensi setiap aktivitas dan kemudian dihitung persentase untuk setiap perilaku. Analisis data dilakukan dengan 
menghitung frekuensi setiap aktivitas dan kemudian dihitung persentase untuk setiap perilaku. Waktu pengamatan dilakukan mulai pukul 06.00 WITA (waktu turun pohon tidur, dan memulai aktivitas) sampai pukul 17.30 (naik pohon tidur) dengan interval pengamatan adalah 1 menit. Sampel dalam penelitian ini meliputi:

\section{Kelompok Rambo I:}

Individu jantan dewasa ada 9 ekor, jadi jumlah pengambilan sampel data adalah 3 ekor. Individu betina dewasa 24 ekor, jadi jumlah sampel pengambilan data ada 8 ekor. Individu juvenil 23 ekor, jadi jumlah sampel pengambilan data ada 8 ekor. Individu bayi ada 6 ekor, jadi jumlah sampel pengambilan data adalah 2 ekor. Jadi total keseluruhan sampel ada pada saat pengambilan data pada KRI adalah 21 ekor.

\section{Kelompok Rambo II:}

Individu jantan dewasa 6 ekor, jadi jadi jumlah sampel pengambilan data adalah 2 ekor. Individu. Betina dewasa 18 ekor, jadi sampel pengambilan data adalah 6 ekor. Individu juvenil 24 ekor, jadi jumlah sampel pengambilan data adalah 8 ekor. Individu bayi 3 ekor, jadi jumlah sampel pengambilan data adalah 1 ekor. Jadi total keseluruhan sampel pada saat pengambilan data pada KRII adalah 17 ekor.

Pada pengamatan aktivitas makan, diamati pula jenis pakan yang dikonsumsi. Selanjutnya frekuensi jenis pakan yang dikonsumsi dihitung persentasenya. Strata hutan dibedakan menjadi 6 stratum, Stratum A (>30 m). Stratum B (20-30 m), Stratum C (4-20 m), Stratum D (1-4 m), dan Stratum E (0-1 m) ( Arif, 1994 dan Indriyanto, 2006), Data pemanfaatan strata vegetasi diambil dengan menggunakan metode metode focal animal sampling (Martin \& Bateson, 1999)

\section{HASIL DAN PEMBAHASAN}

Hasil penghitungan persentase aktivitas harian kedua kelompok disajikan pada Tabel 1. Dari tabel tersebut, persentase aktivitas harian Macaca nigra pada kedua kelompok, yaitu KRI dan KRII berbeda.
Tabel 1. Persentase Aktivitas Harian KRI dan KRII

\begin{tabular}{|c|c|c|c|}
\hline No. & \multirow{2}{*}{ Aktivitas } & \multicolumn{2}{|c|}{$\begin{array}{c}\text { Persentase } \\
(\%)\end{array}$} \\
\cline { 3 - 4 } & & KRI & KRII \\
\hline 1. & Makan & 31 & 28 \\
\hline 2. & Mencari Makan & 18 & 12 \\
\hline 3. & Berpindah & 21 & 22 \\
\hline 4. & Istirahat & 21 & 24 \\
\hline 5. & Allogrooming & 5 & 8 \\
\hline 6. & Agonistik & 1 & 1 \\
\hline 7. & Seksual & 1 & 1 \\
\hline 8. & Bermain & 3 & 4 \\
\hline TOTAL & & 100 & 100 \\
\hline
\end{tabular}

Hasil uji Chi-Square diperoleh nilai $5,112$ ( $\mathrm{p}<0,65)$ yang menunjukkan bahwa perbedaan frekuensi dalam aktivitas harian kedua kelompok tidak berbeda nyata. Dengan kata lain walaupun kedua kelompok tersebut menempati habitat yang berbeda kondisinya, tetapi frekuensi dalam aktivitas hariannya tidak berbeda nyata.

Habitat merupakan wilayah yang digunakan oleh kelompok monyet selama aktivitas harian dalam luasan area tertentu yang disebut daerah jelajah. Daerah jelajah KRII lebih luas dibandingkan dengan daerah jelajah KRI. Perbedaan luas daerah jelajah dan jarak jelajah harian ini disebabkan terutama oleh kualitas habitat pada daerah jelajah kedua kelompok. Habitat KRII mencakup hutan primer, hutan sekunder, padang ilalang, semak belukar, dan pantai. Semak belukar dengan kualitas daya dukung sangat rendah mencapai luas sekitar 60 ha, padang ilalang/glagah sekitar 20 ha, dan hutan sekunder dengan daya dukung yang rendah mencapai luas sekitar 100 ha. Daerah jelajah KRI mencakup habitat hutan primer dengan daya dukung relatif tinggi, habitat pantai, dan sekitar 20 ha hutan sekunder. Perbedaan luas daerah jelajah dan jarak jelajah harian ini disebabkan terutama oleh kualitas habitat pada daerah jelajah kedua kelompok. Habitat KRII mencakup hutan primer, hutan sekunder, padang ilalang, semak belukar, dan pantai. Semak belukar dengan kualitas daya dukung sangat rendah mencapai luas sekitar 60 ha, padang ilalang/glagah sekitar 20 ha, dan hutan sekunder dengan daya dukung yang rendah mencapai luas sekitar 100 ha. Daerah jelajah 
KRI mencakup habitat hutan primer dengan daya dukung relatif tinggi, habitat pantai, dan sekitar 20 ha hutan sekunder.Perbedaan luas daerah jelajah dan jarak jelajah harian ini disebabkan terutama oleh kualitas habitat pada daerah jelajah kedua kelompok. Habitat KRII mencakup hutan primer, hutan sekunder, padang ilalang, semak belukar, dan pantai. Semak belukar dengan kualitas daya dukung sangat rendah mencapai luas sekitar 60 ha, padang ilalang/glagah sekitar 20 ha, dan hutan sekunder dengan daya dukung yang rendah mencapai luas sekitar 100 ha. Daerah jelajah KRI mencakup habitat hutan primer dengan daya dukung relatif tinggi, habitat pantai, dan sekitar 20 ha hutan sekunder.

Oleh karena itu perbedaan yang tidak nyata antara aktivitas harian KRI dan KRII disebabkan karena kemampuan beradaptasi jenis ini terhadap perbedaan kondisi habitat.

Aktivitas makan merupakan aktivitas yang paling banyak dilakukan oleh kedua kelompok, KRI sebesar $31 \%$ dan KRII sebesar $28 \%$. Frekuensi jenis makanan yang dikonsumsi oleh KRI dan KRII disajikan pada Tabel 2.

Tabel 2. Frekuensi Jenis Makanan

\begin{tabular}{|c|c|c|}
\hline $\begin{array}{c}\text { Jenis } \\
\text { Pakan }\end{array}$ & KRI (\%) & $\begin{array}{c}\text { KRII } \\
(\%)\end{array}$ \\
\hline Buah & 54,4 & 44,6 \\
\hline Daun & 20,0 & 11,9 \\
\hline Pucuk & 1,1 & 1,2 \\
\hline Serangga & 22,2 & 41,4 \\
\hline Jamur & 2,0 & 1,1 \\
\hline Batang & 0,4 & 0,0 \\
\hline Bunga & 0,1 & 0,0 \\
\hline
\end{tabular}

Habitat monyet hitam Sulawesi adalah hutan oleh karena itu makanan yang sering dikonsumsi adalah buah-buahan, dedaunan, serangga, bunga, batang kayu, dan jamur. Monyet hitam Sulawesi dapat disebut sebagai frugivor karena lebih sering mengkonsumsi buah-buahan sekitar 50-70\% (Lee et al., 2002), dan hal ini pun terbukti pada KRI yang mengkonsumsi buah-buahan sebanyak $54 \%$.

Karena lebih banyak mengkonsumsi buah-buahan, maka aktivitas makan KRI banyak terjadi pada stratum A. Stratum A merupakan lapisan atas yang terdiri dari pepohonan yang batangnya tumbuh tinggi, lurus, cabang-cabangnya panjang dan biasanya terdapat tajuk pohon buah-buahan seperti rao (Dracontomelon dao), beringin (Ficus sp.) dan nantu (Palaquium amboinense) (Arief, 1994). Biasanya pepohonan seperti Dracontomelon dao dan Ficus sp. Ini tumbuh sampai ketinggian lebih dari $40 \mathrm{~m}$ sehingga stratum A banyak ditemukan sumber makanan yang berupa buah-buahan. Hal ini yang menyebabkan nilai persentase aktivitas makan KRI pada stratum A adalah 47\%. Pohon-pohon buah ini sangart banyak ditemukan di daerah Tangkoko dan hal inilah yang merangsang KRI untuk lebih banyak mengkonsumsi buah-buahan tersebut.

Sama halnya dengan KRI, KRII pun banyak mengkosumsi buah-buahan. Akan tetapi persentase makan lebih banyak terjadi pada stratum B dan C yaitu $44 \%$ dibandingkan dengan stratum A yang hanya $40 \%$. Persentase pemanfaatan stratum B dan C cukup tinggi, disebabkan oleh jenis makannan pada kedua strata ini lebih bervariasi. Stratum B dan C juga ditempati tajuk pepohonan yang bisa dijadikan makanan seperti, kenanga (Canangium odoratum), momaling (Leea indica), mengkudu (Morinda sp.), gora hutan (Eugenia sp.). Pada stratum B dan C selain ditemukan serangga, sehingga keanekaragaman jenis makanan lebih tinggi pada stratum B dan C di daerah jelajah KRII.

Pada habitat KRII banyak ditemukan serangga karena daerah jelajah KRII kebanyakan meliputi daerah bersemak yang lebih banyak didominasi oleh hewan invertebrata. Hal ini juga didukung dengan pernyataan Lee et al. (2001), bahwa monyet hitam Sulawesi yang hidup didearah bersemak atau hutan sekunder lebih mengkonsumsi serangga seperti jangkrik dan kumbang. Meski monyet hitam Sulawesi seringkali disebut hewan frugivor dengan $70 \%$ memakan buah-buahan, tidak menutup kemungkinan bagi KRII lebih banyak mengkonsumsi serangga. Pada daerah jelajah KRII yang merupakan hutan sekunder lebih didominasi oleh alang-alang (Impera cylindrica) dan rerumputan.

Selain itu juga monyet yang sering hidup di habitat seperti ini dikenal'penjarah pertanian seperti mangga, jagung, pepaya, dan kelapa (Lee et al., 2002). Hal ini terlihat pada KRII yang hidup didaerah bersemak yang lebih banyak mengkonsumsi buah 
mangga dan kelapa yang merupakan buahbuahan pertanian pada stratum B dan C. Habitat dari KRII ini tidak alami habitat KRI karena sebagian daerah jelajahnya telah terjamah oleh manusia untuk perkebunan sehingga jenis makanan adalah serangga dan buah-buahan tanaman pertanian.

Berbeda dengan stratum D dan E, kedua strata ini lebih sedikit porsinya dimanfaatkan untuk aktivitas makan kedua kelompok. Pada kedua strata ini jarang ditemukan pohonpohon buah yang enak dikonsumsi. Pada stratum D tumbuha tanaman herba besar, tumbuh-tumbuhan kecil/penutup tanah atau pohon-pohon muda yang produktivitas buahnya kecil (Arief, 1994). Pada stratum E banyak ditemukan rerumputan dan jamur yang jumlahnya sangat sedikit. Pada kedua stratum ini kedua kelompok hanya memakan dedaunan, jamur, buah-buahan, atau bijibijian yang telah jatuh dipermukaan tanah. Terlihat jelas pada tabel-tabel di atas bahwa makan memiliki porsi yang relatif stabil pada setiap stratum dan tidak terlihat perbedaan yang terlalu jauh dan signifikan pada kelima stratum tersebut.

Menurut Frankie et al. (1994) dalam Oates (2002), hutan hujan tropis sangat bergantung pada keadan musim, produktivitasnya akan meningkat bila musim panas ataukering dan pada musim basah produktivitas vegetasi baik daun, buah, dan bunga meningkat.

Pada saat pengambilan data ternyata ditemukan salah satu catatan penting, bahwa monyet hitam Sulawesi yang telah tua jarang sekali mengambil buah-buahan atau makanan di stratum A karena ketidakmampuannya untuk menjangkau area tersebut, sehingga ia hana memunggut buah-buah yang jatuh ke permukaan tanah yaitu pada stratum E. Walaupun daerah jelajah atau pun habitat hidup dari KRI Dan KRII berbeda tetapi persentase aktivitas makan KRII hampir sama dengan persentase KRI yaitu $28 \%$ dan $31 \%$. Ini berarti aktivitas makannya tetap diutamakan.

\section{KESIMPULAN}

Frekuensi aktivitas harian antara Kelompok Rambo I dan Kelompok Rambo II di Cagar Alam Tangkoko-Batuangus berbeda tidak nyata dan aktivitas yang paling banyak dilakukan adalah makan.

\section{DAFTAR PUSTAKA}

Arif. A. 1994. Hutan: Hakikat dan Pengaruhnya terhadap Lingkungan. Yayasan obor Indonesia. Jakarta.

Groves, C. 2001. Primatet Taxonomy. Smithsonian Institution Press, Washington, pp. 226.

Indrayanto. 2006. Ekologi Hutan. Penerbit Bumi Aksara. Jakarta.

Lee RJ and Kussoy P. 1999. Assesment of Wildlife Populations, Forest and Forest Resource Use on Talise Island, North Sulawesi, Indonesia. Proyek Pesisir; Jakarta.

Lee, R.J., J. Riley, and R. Merrill. 2001. Keanekaragaman Hayati dan Konservasi di Sulawesi Bagian Utara. Jakarta: Wildlife Conservation Societies (WCS), Natural Resources, dan Departemen Kehutanan.

Martin, P. and Bateson, P. 1999. Measuring behaviour: An introductory guide. Second Edition, Cambridge University Press, Cambridge, pp. 84-85.

Oates, J. 2002. Food Distribution and Foraging Behavior. Cambridge University. New York.

O,brien TG and Kinnaird MF. 1997. Behavior, Diet, and Movement of Sulawesi Crested Black Macaque (Macaca nigra). Int. J. primatol; 18: 321-351.

Supriatna J. \& E.H. Wahyono. 2000. Panduan Lapangan Primata Indonesia. Yayasan Obor Indonesia. Jakarta

Whitten, A.J., M. Mustafa, and G.S. Henderson. 1988. The Ecology of Sulawesi. Gadjah Mada University Press, Yogyakarta. 